To reduce cancer as the leading cause of work-related deaths in the EU, six key European institutes took the initiative to develop a voluntary action scheme to raise awareness about the risks arising from exposure to carcinogens in the workplace and exchange of good practices. This action scheme is titled 'Roadmap on carcinogens' and runs up until 2019.

The roadmap aims to raise awareness and practical knowledge exchange. Identifying smart solutions and sharing good practices between businesses and organisations, could make a tremendous difference. How? It would reduce workers' exposure to carcinogens, and it would improve the survival of many workers today and tomorrow. One of the main aims of the Roadmap on carcinogens is to share solutions between companies and organisations. Across Europe many initiatives are already being taken by local companies and organisations to apply solutions and prevent or reduce carcinogen exposure. The aim of the Roadmap is to propel these solutions towards innovative practices that are used across Europe. Therefore, sharing best practices and ideas about preventing and reducing exposure to carcinogens at work with the rest of Europe is encouraged. The second aim of the Roadmap on carcinogens is to encourage and help others to raise awareness and share knowledge. The roadmap will function as the hub of activities undertaken in industries, companies and governments. In the presentation several good practices, events and the network of the roadmap will be discussed.

\section{C GOOD PRACTICES TO PREVENT OCCUPATIONAL CANCER FROM EXPOSURE TO HAZARDOUS SUBSTANCES}

Wouter Fransman. TNO, Zeist, The Netherlands

10.1136/oemed-2018-ICOHabstracts.649

In the EU, 100000 to 150000 people are diagnosed with cancer caused by exposure to carcinogenic substances during their work every year. This exposure causes a lot of personal injury and considerable social costs, also in comparison with other causes of death. Exposure to carcinogens is a major risk factor; good reason to address this by prevention at the source. This can be done by substitution of carcinogenic substances or processes, or by design of workplaces and tools in combination with frequent and careful use of dust-free tools and other good practices. The improvement potential is high and there are currently good initiatives in various sectors that create a healthy work environment. The currently available technological solutions offer great potential for improvement to reduce exposure. By better implementation, enforcement and information a lot of health profit will be gained. In order to work well, it is also important that workers are aware of the risks of carcinogens in their daily work. It is important to educate workers about the risks and the available solutions. For many of the control measures and good practices, the conditions are favourable, because there is a legal necessity: meeting the occupational exposure limit, contributing to good employment, funds are available and purchase costs are limited and cost reduction is possible on material costs and reduced cleaning costs. There are also a number of good initiatives and thus it seems possible to achieve a big effect. This presentation will give insight into various good practices and innovative technical solutions and methods in a variety of industries, which are currently available. When widely applied these good practices can heavily reduce work-related cancer in those sectors.

\section{THE NEW ILO LIST OF OCCUPATIONAL DISEASES: GUIDANCE NOTES ON DIAGNOSTIC CRITERIA FOR OCCUPATIONAL DISEASES INCLUDED IN THE ILO LIST}

${ }^{1}$ Claudio Colosio, ${ }^{2}$ Shengli Niu, ${ }^{3}$ Gert van der Laan. ${ }^{1}$ Department of Health Sciences of the University of Milan and International Centre for Rural Health of the ASTT Saints Paolo and Carlo Hospital, Milan, Italy; ${ }^{2}$ International Labour Organisation, Geneva, Switzerland; ${ }^{3}$ Foundation Learning and Developing Occupational Health, PE Leusden, Netherlands

\subsection{6/oemed-2018-ICOHabstracts.650}

Aim of special session In 2010 the new ILO list of occupational diseases was adopted, which was established for prevention, diagnosis and compensation of occupational diseases. After the adoption, an international experts group was set up to help the International Labour Office in the preparation of guidance notes on the diagnostic criteria for the occupational diseases included in the ILO list. This group has kept a lose contact with the WHO working group on occupational diseases in ICD11. The notes cover all the groups of diseases included in the ILO list (more than 100 monographs in total. The notes also include a part on prevention in relation to each disease or diseases' groups. This minisymposium is organised to provide background information on the major issues in the process of the preparation for the Guidance Notes, the role and application of these notes, the linkage between the ILO list and the WHO ICD, the national practice and expertise on the recognition of OD. Interaction between the invited presenters and audiences is included on the arrangement of this minisymposium. During the preparation of the workshop. Prof. Tar Chin Aw suddenly passed away, Prof. Colosio will deliver a presentation also on the name of the colleague who participated in the preparation of the event and was supposed to provide a presentation.

Shengli Niu ${ }^{2}$, Anil Adisesh ${ }^{4}$, Claudio Colosio ${ }^{1}$, Jorma Rantanen $^{5}$, Swen Malte John ${ }^{6}$, Igor Bukhtiyarov ${ }^{7}$, Zhang Min ${ }^{8}$, Linda Forst ${ }^{9}$, Annet F. Lenderink ${ }^{10}$, Ivan Ivanov ${ }^{11}$

${ }^{1}$ Department of Health Sciences of the University of Milan and International Centre for Rural Health of the S. Paolo Hospital, Italy

${ }^{2}$ International Labour Organisation, Geneva, Switzerland

${ }^{3}$ Foundation Learning and Developing Occupational Health, Speelkamp 28, 3831 PE Leusden, The Netherlands Finnish Institute of Occupational Health, Centre of Expertise for Development of Work and Organisations, Topeliuksenkatu 41 a A, 00250 Helsinki, Finland Solvent Team Amsterdam, Netherlands Centre for Occupational Diseases, Coronel Institute of Occupational Health, Academic Medical Centre, University of Amsterdam, Meibergdreef 9, 1105 AZ Amsterdam, The Netherlands

${ }^{4}$ Dalhousie University, Halifax, Canada

${ }^{5}$ University of Helsinki, Department of Public Health/Occupational Health, Helsinki, Finland

${ }^{6}$ Dept. Dermatology, Environmental Medicine, Health Theory, University of Osnabrueck, Osnabrueck, Germany

${ }^{7}$ FSBSI 'Izmerov Research Institute of Occupational Health', Moscow, Russia

${ }^{8}$ Chinese Academy of Medical Sciences (CAMS)/Peking Union Medical College (PUMC), Beijing, China

${ }^{9}$ University of Illinois at Chicago School of Public Health, Illinois, US 